\title{
IDENTIFIKASI MISKONSEPSI FISIKA PADA SISWA SMAN DI KOTA PALU
}

\author{
Nursarifa zahra, Kamaluddin dan Muslimin \\ NhurZahra999@yahoo.co.id \\ Program Studi Pendidikan Fisika FKIP Universitas Tadulako \\ Jl. Soekarno Hatta Km. 9 Kampus Bumi Tadulako Tondo Palu - Sulawesi Tengah
}

\begin{abstract}
Penelitian ini bertujuan mendeskripsikan miskonsepsi yang terjadi pada siswa SMAN Di Kota Palu yang teridentifikasi melalui metode Certainty of response index (CRI) yaitu derajat kepastian/keyakinan. Penelitian ini merupakan penelitian deskriptif-kualitatif. Subjek penelitian berjumlah 122 orang yang dipilih berdasarkan pertimbangan peneliti. Analisa data melalui tes diagnostik sebanyak 20 soal yang telah divalidkan oleh judgement ahli, tes tersebut berupa multiple coice dilengkapi dengan CRI sehingga kesulitan responden dalam menjawab tes tersebut dapat diketahui. Hasil jawaban siswa memiliki miskonsepsi dengan persentase 48,93\%. Hal ini menunjukkan bahwa miskonsepsi SMAN Di Kota Palu mengalami miskonsepsi cukup tinggi. Maka perlu adanya perhatian dan remediasi mengenai materi Suhu dan Kalor karena akan mempengaruhi konsep siswa ke jenjang berikutnya.
\end{abstract}

Kata Kunci: Identifikasi, Miskonsepsi

\section{PENDAHULUAN}

Fisika adalah ilmu pengetahuan yang dibangun atas dasar fakta bukan berdasarkan opini atau pendapat. Fakta didapatkan dari data penelitian yang memiliki nilai yang sangat tinggi, sedangkan opini adalah hasil pemikiran. Tingkat kualitas fakta sangat ditentukan oleh keandalan dan ketelitian data yang dihasilkan oleh penelitinya. Berbagai fakta kejadian atau fenomena yang dibahas di dalam fisika baik yang berukuran besar (bersifat makroskopis) maupun yang berukuran kecil (mikroskopis). Fenomena itu dirumuskan secara matematis dan dijadikan sebagai teori sehingga dapat dimengerti secara pasti oleh manusia untuk kemanfaatan umat manusia.

Pengetahuan awal siswa sangat penting dalam proses pembelajaran sering kali pengetahuan awal tersebut tidak cocok dengan pengetahuan dengan para pakar dan menjadi suatu miskonsepsi. Prakonsepsi yang dimiliki oleh siswa menunjukkan bahwa pikiran anak sejak lahir tidak diam, tetapi terus memahami sesuatu. Sejak kecil anak berpengalaman dengan alam di sekitarnya, anak yang menggerakkan mainan telah memperoleh pengalaman yang berhubungan dengan konsep-konsep fisika, maka di dalam otaknya sudah terbentuk konsepsi atau miskonsepsi yang berhubungan dengan konsep-konsep tersebut ${ }^{[1]}$.

Miskonsepsi merupakan kecenderungan bahwa siswa memiliki konsepsi yang berbeda satu dengan yang lainnya. Beberapa diantara siswa tersebut ada yang memilki konsepsi berbeda dengan konsepsi ilmuan, konsepsi ilmuan biasanya lebih kompleks, lebih rumit dan lebih banyak melibatkan keterkaitan antar konsep. Jika konsepsi siswa ternyata sama dengan konsepsi ilmuan yang telah disederhanakan, maka konsepsi tersebut tidak dinyatakan salah. Sedangkan konsepsi siswa bertentangan dengan konsepsi yang telah disederhanakan maka siswa tersebut dinyatakan mengalami kesalahan konsepsi atau miskonsepsi ${ }^{[2]}$.

Beberapa fakta yang diungkap melalui penelitian sebelumnya diantaranya yang berhasil mengungkapkan fakta bahwa siswa masih mengalami miskonsepsi fisika dan tingkat pemahaman konsep yang masih sangat minim, meskipun materi ini sudah mereka dapatkan di tingkat sekolah menengah pertama $(\mathrm{SMP})^{[3]}$. Kemudian fakta penelitian selanjutnya yang berhasil mengungkapkan bahwa siswa MAN 1 X.2 dan X.3 Bukittinggi mengalami miskonsepsi suhu dan kalor cukup tinggi ${ }^{[4]}$.

Miskonsepsi pada siswa yang muncul secara terus menerus dapat mengganggu pembentukan konsepsi ilmiah. Pembelajaran yang tidak memperhatikan miskonsepsi menyebabkan kesulitan belajar dan akhirnya akan bermuara pada rendahnya prestasi belajar siswa. Hal ini sering terjadi pada semua tingkatan baik SD, sampai dengan perguruan tinggi bahkan gurupun dapat mengalami miskonsepsi. Pada akhirnya, bila tidak segera diperbaiki miskonsepsi tersebut akan menjadi 
hambatan bagi siswa pada proses pembelajaran lanjut.

Pengidentifikasian miskonsepsi merupakan hal yang mendasar untuk diketahui sebelum lebih jauh membicarakan upaya penanggulangan miskonsepsi, karena dengan adanya identifikasi maka berguna untuk membedakan siswa yang tidak tahu konsep dan siswa yang miskonsepsi sehingga timbul bagaimana cara menanggulanginya. Salah satu yang sering terjadi miskonsepsi fisika siswa SMA yaitu Suhu dan kalor. Materi ini akan menjadi dasar siswa untuk mempelajari termodinamika. Sebagai contoh salah satu penelitian yang menyatakan bahwa banyak siswa mempunyai pengertian suatu benda yang mempunyai suhu lebih tinggi selalu mempunyai panas yang lebih tinggi $\mathrm{i}^{[5]}$.

Berdasarkan beberapa fakta mengenai miskonsepsi pada konsep-konsep Fisika, maka hal inilah yang menarik bagi peneliti untuk melakukan identifikasi miskonsepsi Fisika terkait dengan materi Suhu dan Kalor pada siswa SMAN di Kota Palu menggunakan metode CRI (Certainty of Response Index).

\section{METODE PENELITIAN}

Penelitian ini merupakan penelitian yang bertujuan untuk memberikan gambaran terkait dengan identifikasi miskonsepsi fisika siswa SMA Negeri Di Kota Palu. Konsep fisika yang diteliti dibatasi pada materi Suhu dan Kalor. Penelitian ini termasuk penelitian kualitatif yang mendeskripsikan fakta, fenomena yang terjadi pada subjek penelitian. Sebagaimana diungkapkan Sukmadinata ${ }^{[6]}$ bahwa penelitian deskriptif ditujukan untuk mendeskripsikan atau menggambarkan fenomena-fenomena yang ada, baik fenomena yang bersifat alamiah ataupun rekayasa manusia. Adapun desain yang digunakan dalam penelitian ini yaitu desain studi deskriptif karena dalam penelitian ini hanya difokuskan pada satu fenomena saja yang ingin dipahami secara mendalam, dengan mengabaikan fenomena-fenomena lainnya dan akan dideskripsikan miskonsepsi fisika berupa tes diagnostik multiple coice materi Suhu dan Kalor dengan metode Certainty of response index (CRI). Untuk membedakan antara tahu konsep, dan miskonsepsi dapat menggunakan ketentuan yang digunakan oleh Tayubi, $Y . \mathrm{R}^{[7]}$. Dapat dilihat pada tabel 1 .

Tabel 1. Kriteria Pengelompokan jawaban siswa berdasarkan CRI

\begin{tabular}{|l|l|l|}
\hline $\begin{array}{l}\text { Kriteria } \\
\text { jawaban }\end{array}$ & $\begin{array}{l}\text { CRI Rendah ( } \\
<2,5)\end{array}$ & CRI Tinggi ( >2,5) \\
\hline $\begin{array}{l}\text { Jawaban } \\
\text { benar }\end{array}$ & $\begin{array}{l}\text { Jumlah jawaban } \\
\text { yang benar tapi } \\
\text { CRI rendah berarti } \\
\text { tidak tahu konsep } \\
\text { (Lucky Guess) }\end{array}$ & $\begin{array}{l}\text { Jumlah jawaban } \\
\text { yang benar tapi } \\
\text { CRI tinggi, berarti } \\
\text { pengetahuan } \\
\text { konsep y yang } \\
\text { benar }\end{array}$ \\
\hline $\begin{array}{l}\text { Jawaban } \\
\text { salah }\end{array}$ & $\begin{array}{l}\text { Jawaban salah dan } \\
\text { CRI rendah berarti } \\
\text { tidak tahu konsep }\end{array}$ & $\begin{array}{l}\text { Jawaban salah } \\
\text { tapi CRI tinggi } \\
\text { berarti terjadi } \\
\text { miskonsepsi }\end{array}$ \\
\hline
\end{tabular}

Analisa data terhadap hasil penelitian meliputi Analisis terhadap distribusi kategori responden dan Analisis terhadap distribusi responden yang dalam kategori: lucky guess (menjawab benar dengan menebak), a lack of knowledge (kekurangan pengetahuan), miskonsepsi dan benar-benar memahami konsep.

\section{HASIL PENELITIAN DAN PEMBAHASAN}

Berdasarkan hasil analisis jawaban siswa maka diperoleh data kuantitatif dari nilai CRI yang dituliskan oleh subjek penelitian pada tes multiple coice (pilihan ganda). Subjek yang digunakan pada penelitian ini siswa SMA Negeri di Kota Palu sebanyak 122 siswa yang berada pada sekolah yang berbeda. Hasil analisis menunjukkan bahwa terjadi miskonsepsi Fisika pada siswa SMA Negeri di Kota Palu sebesar 48,93 \%. Selebihnya yaitu menebak sebesar $11,43 \%$, mengerti sebesar $32,38 \%$ dan kurang pengetahuan sebesar 7,25 $\%$. Variasi miskonsepsi pada materi suhu dan kalor dapat dilihat pada tabel 2.

Tabel. 4.2. Miskonsepsi siswa pada materi suhu dan kalor

\begin{tabular}{|c|c|c|c|c|c|c|}
\hline $\begin{array}{c}\text { No } \\
\text { Soa } \\
\text { I }\end{array}$ & Konsep & \multicolumn{4}{|c|}{ Kategori } & \multirow{2}{*}{$\begin{array}{c}\text { Tingkat } \\
\text { keyakin } \\
\text { an } \\
\text { (CRI) } \\
(\%)\end{array}$} \\
\hline & $\begin{array}{c}\text { Mene } \\
\text { bak } \\
(\%)\end{array}$ & $\begin{array}{c}\text { Meng } \\
\text { erti } \\
(\%)\end{array}$ & $\begin{array}{c}\text { Kurang } \\
\text { penget } \\
\text { ahuan } \\
(\%)\end{array}$ & $\begin{array}{c}\text { Misko } \\
\text { nseps } \\
\text { i (\%) }\end{array}$ & $\begin{array}{c}\text { yang } \\
\text { diguna } \\
\text { kan } \\
\text { untuk } \\
\text { menaik } \\
\text { kan } \\
\text { suhu }\end{array}$ \\
\hline 2. & 4,10 & 33,61 & 2,46 & 59,84 & 3,60 \\
\hline $\begin{array}{c}\text { Pengar } \\
\text { uh } \\
\text { suhu } \\
\text { terhada } \\
\text { p } \\
\text { ukuran } \\
\text { benda }\end{array}$ & 6,56 & 21,31 & 3,28 & 68,85 & 3,69 \\
\hline 3. & $\begin{array}{c}\text { Pengar } \\
\text { uh } \\
\text { suhu }\end{array}$ & 5,74 & 16,39 & 9,84 & 68,03 & 3,22 \\
\hline
\end{tabular}




\begin{tabular}{|c|c|c|c|c|c|c|}
\hline & $\begin{array}{c}\text { terhada } \\
\mathrm{p} \\
\text { ukuran } \\
\text { benda }\end{array}$ \\
\hline & $\begin{array}{c}\text { Pengar } \\
\text { uh } \\
\text { suhu } \\
\text { terhada } \\
\mathrm{p} \\
\text { ukuran } \\
\text { benda }\end{array}$ \\
5 & $\begin{array}{c}\text { Penga } \\
\text { matan } \\
\text { termo } \\
\text { meter }\end{array}$ & 11,48 & 18,85 & 4,92 & 64,75 & 3,44 \\
\hline & 85,25 & 0,82 & 1,64 & 3,79 \\
\hline
\end{tabular}

\begin{tabular}{|c|c|c|c|c|c|c|}
\hline & & $\begin{array}{c}\text { Mene } \\
\text { bak } \\
(\%)\end{array}$ & $\begin{array}{c}\text { Meng } \\
\text { erti } \\
(\%)\end{array}$ & $\begin{array}{c}\text { Kuran } \\
\text { g } \\
\text { penge } \\
\text { tahua } \\
\mathrm{n}(\%)\end{array}$ & $\begin{array}{c}\text { Mis } \\
\text { kon } \\
\text { sep } \\
\text { si } \\
(\%)\end{array}$ & $\begin{array}{c}\text { an } \\
\text { (CRI) } \\
(\%)\end{array}$ \\
\hline 6. & $\begin{array}{c}\text { Hubung } \\
\text { an } \\
\text { kalor } \\
\text { terhada } \\
\text { p suhu } \\
\text { suatu } \\
\text { benda }\end{array}$ & 2,46 & 25,41 & 4,10 & $\begin{array}{c}68, \\
03\end{array}$ & 3,56 \\
\hline 7. & $\begin{array}{c}\text { Hubung } \\
\text { an } \\
\text { kalor } \\
\text { dengan } \\
\text { massa } \\
\text { zat } \\
\end{array}$ & 12,30 & 68,85 & 9,84 & $\begin{array}{c}9,0 \\
2\end{array}$ & 3,50 \\
\hline 8. & $\begin{array}{l}\text { Kalor } \\
\text { jenis }\end{array}$ & 11,48 & 13,93 & 11,48 & $\begin{array}{c}63 \\
11 \\
\end{array}$ & 3,04 \\
\hline 9. & $\begin{array}{c}\text { Hubung } \\
\text { an } \\
\text { kalor } \\
\text { dengan } \\
\text { massa } \\
\text { jenis } \\
\text { zat } \\
\end{array}$ & 24,59 & 53,28 & 6,56 & $\begin{array}{l}15, \\
57\end{array}$ & 3,06 \\
\hline 10. & $\begin{array}{c}\text { Grafik } \\
\text { hubung } \\
\text { an } \\
\text { kalor } \\
\text { dengan } \\
\text { peruba } \\
\text { han } \\
\text { suhu }\end{array}$ & 45,90 & 36,89 & 6,56 & $\begin{array}{c}10 \\
66\end{array}$ & 2,49 \\
\hline
\end{tabular}

Pada tabel 2. Konsep kalor yang digunakan untuk menaikkan suhu menunjukkan bahwa proporsi responden miksonsepsi sebesar 59,83 \%. Pada umumnya siswa beranggapan bahwa kalor itu sesuatu yang disimpan oleh suatu benda. Hal ini sesuai dengan pilihan jawaban yang dominan dipilih oleh siswa yang mana fakta yang diuangkapkan oleh salah satu peneliti mengenai konsep pengaruh kalor dalam perubahan suhu suatu zat banyak siswa yang belum paham mengenai kalor $^{[8]}$. Namun konsep yang benar yaitu kalor yang diterima air digunakan untuk menaikkan suhu.

Pada konsep pengaruh suhu terhadap ukuran benda menunjukkan bahwa proporsi responden miksonsepsi sebesar 68,85\%. Siswa menganggap bahwa suhu yang dicapai suatu benda bergantung pada ukurannya. Konsep yang benar yaitu suhu balok es akan sama besar bagaimanapun dipotong. Selain itu, ada dua konsep yang sama tentang pengaruh suhu terhadap ukuran benda tetapi bentuk soal yang berbeda. Pertama, Siswa menganggap bahwa tingkat suhu suatu benda bergantung pada ukurannya dengan proporsi responden miksonsepsi sebesar 68,03\%. Konsep yang benar yaitu apabila Es yang diambil dari lemari es yang sama maka suhunya akan sama meskipun memiliki ukuran yang berbeda. Kedua, Siswa tidak memperhatikan bahwa pengaruh lingkungan diabaikan ketika menuangkan air tersebut di gelas yang berbeda. Konsep ilmiahnya yaitu suhu air panas tetap sama meskipun berada di gelas yang berbeda. Pada konsep pengamatan termometer menunjukkan bahwa siswa dominan mengerti konsep sesuai dengan pilihan jawaban siswa.

Tabel 3. Miskonsepsi siswa pada materi kalor

\begin{tabular}{|c|c|c|c|}
\hline $\begin{array}{c}\text { No. } \\
\text { Soal }\end{array}$ & Konsep & Kategori & $\begin{array}{c}\text { Tingkat } \\
\text { keyakin }\end{array}$ \\
\hline
\end{tabular}


Semakin kecil kalor jenis benda, semakin baik kemampuan benda tersebut menyerap atau melepaskan kalor. Selanjutnya hubungan kalor dengan massa jenis zat menunjukkan bahwa siswa mengerti konsep yang menyatakan bahwa minyak goreng lebih dahulu mencapai suhu yang ditentukan dibandingkan air karena kalor jenis kedua benda berbeda. Sedangkan konsep grafik hubungan kalor dengan perubahan suhu siswa lebih banyak menebak tentang konsep.

Tabel 4. Miskonsepsi siswa pada materi kalor

\begin{tabular}{|c|c|c|c|c|c|c|}
\hline $\begin{array}{l}\text { No. } \\
\text { Soa }\end{array}$ & Konsep & \multicolumn{4}{|c|}{ Kategori } & \multirow{2}{*}{$\begin{array}{c}\text { Tingk } \\
\text { at } \\
\text { keyaki } \\
\text { nan } \\
\text { (CRI) } \\
(\%)\end{array}$} \\
\hline & & $\begin{array}{c}\text { Mene } \\
\text { bak } \\
(\%)\end{array}$ & $\begin{array}{c}\text { Meng } \\
\text { erti } \\
(\%)\end{array}$ & $\begin{array}{c}\text { Kuran } \\
\text { g } \\
\text { penge } \\
\text { tahua } \\
\mathrm{n}(\%)\end{array}$ & $\begin{array}{l}\text { Misko } \\
\text { nseps } \\
\mathrm{i}(\%)\end{array}$ & \\
\hline 11. & $\begin{array}{c}\text { Muai } \\
\text { panjang }\end{array}$ & 3,28 & 18,85 & 13,11 & 64,75 & 3,19 \\
\hline 12. & $\begin{array}{c}\text { Perubaha } \\
\text { n wujud } \\
\text { dari } \\
\text { padat } \\
\text { menjadi } \\
\text { cair }\end{array}$ & 3,28 & 23,77 & 4,92 & 68,03 & 3,65 \\
\hline 13. & $\begin{array}{c}\text { Penguap } \\
\text { an }\end{array}$ & 4,92 & 22,13 & 9,02 & 63,93 & 3,55 \\
\hline 14. & $\begin{array}{l}\text { Mengem } \\
\text { bun }\end{array}$ & $\begin{array}{c}31,9 \\
7\end{array}$ & 42,62 & 4,92 & 20,49 & 2,98 \\
\hline 15. & $\begin{array}{c}\text { Grafik } \\
\text { fase } \\
\text { perubaha } \\
\text { n wujud }\end{array}$ & 2,46 & 13,11 & 9,84 & 74,59 & 3,50 \\
\hline
\end{tabular}

Pada tabel 4. Konsep muai panjang menunjukkan bahwa proporsi responden miskonsepsi sebesar 64,75 \%, sedangkan mengenai konsepsi ilmiah cukup rendah. Pilihan jawaban siswa dominan miskonsepsi yaitu siswa menganggap bahwa partikelpartikel kalor memenuhi ruang antar partikel alumunium, sehingga partikel-partikel alumunium terdesak ke segala arah. Konsep yang benar yaitu Suatu benda yang dipanaskan mengalami pemuaian karena jarak antar partikel menjadi semakin jauh akibat kenaikan suhu.

Pada konsep perubahan wujud dari padat menjadi cair menunjukkan bahwa proporsi responden miskonsepsi sebesar 68,03 $\%$. Pilihan jawaban siswa dominan miskonsepsi yaitu siswa mengganggap Es melepaskan kalor. Hal ini berarti siswa belum mengerti proses perubahan wujud mana yang melepaskan kalor dan mana yang menerima kalor. Konsep yang benar yaitu terjadi perubahan wujud dari es menjadi air karena es menerima kalor dari lingkungan akibat adanya perbedaan suhu.

Pada Konsep penguapan menunjukkan bahwa proporsi responden miskonsepsi sebesar $63,93 \%$. Pilihan jawaban siswa dominan miskonsepsi yaitu siswa menganggap jika suhu air yang sedang mendidih tidak akan naik lagi meskipun terus dipanaskan maka kalor tersebut dilepaskan ke udara sekitar secara konveksi. Kita ketahui bahwa konveksi yang terjadi pada gas dan zat cair. Pernyataan siswa tersebut benar namun tidak ada hubungannya dengan perubahan wujud cair menjadi gas. Pada konsep mengembun siswa lebih banyak mengerti konsep.

Pada Konsep grafik fase perubahan wujud menunjukkan bahwa proporsi responden miskonsepsi sebesar 74,59 \%. siswa memilih jawaban yang tidak sesuai dengan grafik. Sehingga dapat di simpulkan bahwa siswa tidak paham dalam mengartikan grafik.

Tabel 5. Miskonsepsi siswa pada materi kalor

\begin{tabular}{|c|c|c|c|c|c|c|}
\hline $\begin{array}{l}\text { No } \\
\text { So }\end{array}$ & $\begin{array}{l}\text { Kon } \\
\text { sep }\end{array}$ & \multicolumn{4}{|c|}{ Kategori } & \multirow{2}{*}{$\begin{array}{c}\text { Tingk } \\
\text { at } \\
\text { keya } \\
\text { kinan } \\
(\mathrm{CRI}) \\
(\%)\end{array}$} \\
\hline & & $\begin{array}{c}\text { Mene } \\
\text { bak } \\
(\%)\end{array}$ & $\begin{array}{c}\text { Meng } \\
\text { erti } \\
(\%)\end{array}$ & $\begin{array}{c}\text { Kuran } \\
\text { g } \\
\text { peng } \\
\text { etahu } \\
\text { an } \\
(\%)\end{array}$ & $\begin{array}{c}\text { Misko } \\
\text { nsepsi } \\
(\%)\end{array}$ & \\
\hline $\begin{array}{c}16 \\
.\end{array}$ & $\begin{array}{c}\text { Kon } \\
\text { duks } \\
\mathrm{i}\end{array}$ & 20,49 & 56,56 & 9,84 & 13,11 & 3,05 \\
\hline $\begin{array}{c}17 \\
.\end{array}$ & $\begin{array}{c}\text { Kon } \\
\text { veks } \\
\text { i }\end{array}$ & 2,46 & 14,75 & 9,84 & 72,95 & 3,45 \\
\hline $\begin{array}{c}18 \\
.\end{array}$ & $\begin{array}{c}\text { Radi } \\
\text { asi }\end{array}$ & 5,74 & 6,56 & 13,11 & 74,59 & 3,11 \\
\hline $\begin{array}{c}19 \\
.\end{array}$ & $\begin{array}{c}\text { Pert } \\
\text { ukar } \\
\text { an } \\
\text { kalo } \\
r\end{array}$ & 0 & 0 & 6,56 & 93,44 & 3,50 \\
\hline $\begin{array}{c}20 \\
.\end{array}$ & $\begin{array}{c}\text { Asas } \\
\text { blac } \\
\mathrm{k}\end{array}$ & 17,21 & 75,41 & 4,10 & 3,28 & 3,70 \\
\hline
\end{tabular}

Pada tabel 5. konsep konduksi menunjukkan bahwa siswa dominan mengerti konsep. Pada konsep konveksi menunjukkan bahwa proporsi responden miskonsepsi sebesar $72,95 \%$. Siswa menganggap bahwa 
pemanasan batang logam termasud konveksi. Hal ini berarti siswa tidak paham dalam membedakan konduksi dan konveksi.

Pada Konsep radiasi menunjukkan bahwa proporsi responden miskonsepsi sebesar $73,77 \%$. Pilihan jawaban siswa dominan miskonsepsi yaitu ruang hampa dimaksudkan agar pemindahan panas secara radiasi tidak terjadi. Hal ini menunjukkan bahwa siswa belum mengetahui prinsip kerja termos sesuai dengan penelitian sebelumnya bahwa siswa tidak bisa membedakan fungsi bahan berdasarkan proses yang akan terjadi pada bahan tersebut (contoh termos) ${ }^{[9]}$. Konsep yang benar yaitu termos berfungsi untuk menyimpan zat cair agar tetap terjaga suhunya dalam jangka waktu tertentu. Termos dibuat dengan prinsip mencegah proses perpindahan kalor secara konduksi, konveksi dan radiasi.

Pada konsep pertukaran kalor menunjukkan bahwa proporsi responden miskonsepsi sebesar 93,44 \%. Siswa menganggap bahwa suhu sendok besi lebih tinggi daripada suhu pada sendok plastik karena besi lebih muda menyerap kalor. Hal ini berarti Siswa tidak memperhatikan bahwa persentuhan tangan dengan sendok besi dapat berpengaruh karena kalor dari tangan berpindah ke besi tersebut sehingga suhu pada sendok besi dan sendok plastik sama ketika menggunakan termometer. Pada konsep Asas black menunjukkan bahwa siswa mengerti konsep

\section{KESIMPULAN}

Berdasarkan hasil penelitian yang telah dilakukan maka diperoleh kesimpulan yaitu :

1) Siswa SMAN Di Kota Palu mengalami miskonsepsi materi suhu dan kalor dengan konsep yang bervariasi. Kemudian persentase miskonsepsi yang dialami siswa SMAN Di Kota Palu sebesar 48,93 \%. Hal ini menunjukkan bahwa kesalahpahaman konsep yang dialami oleh siswa cukup tinggi, oleh karena itu kiranya perlu adanya remediasi terhadap konsep-konsep fisika terutama materi suhu dan kalor.

2) Bentuk-bentuk miskonsepsi fisika diantaranya yaitu

a) Konsep kalor yang digunakan untuk menaikkan suhu, siswa beranggapan bahwa kalor itu sesuatu yang disimpan oleh suatu benda. Tetapi konsep yang benar yaitu kalor yang diterima air digunakan untuk menaikkan suhu. b) Konsep pengaruh suhu terhadap ukuran benda, Siswa menganggap bahwa suhu yang dicapai suatu benda bergantung pada ukurannya tetapi konsep yang benar yaitu suhu balok es akan sama besar bagaimanapun dipotong.

c) Konsep pengaruh kalor terhadap suhu suatu benda, siswa menganggap ketika balok besi diletakkan di atas balok kayu maka Kalor dari kayu mengalir ke besi sebab besi lebih cepat panas daripada kayu tetapi konsep yang benar yaitu tidak ada kalor yang mengalir dari besi ke kayu atau sebaliknya sebab suhu kedua benda.

d) Konsep kalor jenis, siswa menganggap bahwa Suhu benda naik lebih cepat jika kalor jenisnya besar sedangkan suhu benda naik lebih lambat jika kalor jenis yang kecil tetapi konsep yang benar yaitu semakin besar kalor jenis suatu benda, semakin kecil kemampuan benda tersebut menyerap atau melepaskan kalor. Semakin kecil kalor jenis benda, semakin baik kemampuan benda tersebut menyerap atau melepaskan kalor.

e) Konsep muai panjang, siswa menganggap bahwa partikel-partikel kalor memenuhi ruang antar partikel alumunium, sehingga partikel-partikel alumunium terdesak ke segala arah tetapi konsep yang benar yaitu suatu benda yang dipanaskan mengalami pemuaian karena jarak antar partikel menjadi semakin jauh akibat kenaikan suhu.

f) Konsep perubahan wujud dari padat menjadi cair, siswa mengganggap Es melepaskan kalor tetapi konsep yang benar yaitu yaitu terjadi perubahan wujud dari es menjadi air karena es menerima kalor dari lingkungan akibat adanya perbedaan suhu.

g) konsep penguapan, siswa menganggap jika suhu air yang sedang mendidih tidak akan naik lagi meskipun terus dipanaskan maka kalor tersebut dilepaskan ke udara sekitar secara konveksi tetapi konsep yang benar yaitu kalor digunakan untuk mengubah molekul air dari keadaan cair menjadi uap (gas)

h) Konsep konduksi, siswa menganggap bahwa pemanasan batang logam termaksud konveksi tetapi konsep yang 
benar yaitu pemanasan batang logam termaksud konduksi.

i) Konsep radiasi, siswa menganggap ruang hampa pada termos dimaksudkan agar pemindahan panas secara radiasi tidak terjadi tetapi konsep yang benar yaitu termos dibuat dengan prinsip mencegah proses perpindahan kalor secara konduksi, konveksi dan radiasi.

j) Konsep pertukaran kalor, Siswa menganggap bahwa suhu sendok besi lebih tinggi daripada suhu pada sendok plastik karena besi lebih muda menyerap kalor tetapi konsep yang benar yaitu suhu pada sendok besi dan sendok plastik sama

\section{DAFTAR PUSTAKA}

[1] Suparno, paul. 2005. Miskonsepsi dan Perubahan Konsep dalam Pendidikan Fisika. Jakarta: PT Grasindo.

[2] Van den Berg, E .1991. Miskonsepsi Fisika dan Remediasi. Salatiga: Universitas Kristen Satya Wacana Press.

[3] Setyadi K.E dan Amir Komalasari. 2012. "Miskonsepsi Tentang Suhu Dan Kalor Pada Siswa Kelas 1 Di Sma Muhammadiyah Purworejo, Jawa Tengah". Berkala Fisika Indonesia Program Studi Pendidikan Fisika UMP. $4,(1 \& 2), 46-49$.

[4] Hafizah, D., Venny Haris dan Eliwatis. 2014. Analisis Miskonsepsi Siswa Melalui Tes Multiple Choice Menggunakan Certainty Of Response Index Pada Mata Pelajaran Fisika Man 1 Bukittinggi. Jurnal Pendidikan MIPA Program Studi Tadri Fisika Jurusan Tarbiyah STAIN Batusangkar. 1 (1), 100-103.

[5] Suparno, paul. 2005. Miskonsepsi dan Perubahan Konsep dalam Pendidikan Fisika. Jakarta: PT Grasindo.

[6] Sukmadinata, Nana Syaodih. (2010). Metode Penelitian Pendidikan. Bandung: Remaja Rosda Karya.

[7] Tayubi, Y. R. 2005. Identifikasi miskonsepsi pada konsep-konsep fisika dengan menggunakan CRI (certainty of response indeks). Bandung: Jurnal Mimbar Pendidikan Jurusan pend. Fisika FPMIPA UPI . No. 3/XXIV,4-9.

[8] Iriyanti, P.N., Sri M dan Sri Retno D.A. (2012). "Identifikasi Miskonsepsi Pada Materi Pokok Wujud Zat Siswa Kelas Vii Smp Negeri 1 Bawang Tahun Ajaran 2009/2010". Jurnal Pendidikan Kimia Program Studi Pendidikan Kimia Universitas Sebelas Maret. 1, (1) , 813.

[9] Suwarna I.P. (2013). "Analisis Miskonsepsi Siswa SMA Kelas X Pada Mata Pelajaran Fisika Melalui CRI (certainty of response indeks) Termodifikasi". Jurnal Laporan Lemlit Analisis Miskonsepsi Dosen Pendidikan Fisika FITK UIN Syarif Hidayatullah Jakarta [online] tersedia:http://repository.uinjkt.ac.id/dspace/bitstrea m/123456789/24028/3/Jurnal\%20Laporan\%20lemlit
\%20Analisis\%20Miskonsepsi\%20(iwan\%20permana\% 20s). [12 $\quad$ September 2014 
Jurnal Pendidikan Fisika Tadulako (JPFT)

Vol. 3 No. 3

ISSN 23383240 